\title{
ENERGY AUDIT, CONSERVATION AND POWER FACTOR IMPROVEMENT FOR BMSIT CAMPUS
}

\author{
Manjunatha Babu $\mathbf{P}^{1}$, T C Balachandra ${ }^{2}$, Ozwin Dsouza $^{3}$, Babu Naik \\ ${ }^{1,3,4}$ Assistant Professor, ${ }^{2}$ Professor and Head of Department, Department of Electrical \& Electronics Engineering, BMS \\ institute of Technology, Yelahanka, Bangalore-560064 \\ manjubabup@gmail.com
}

\begin{abstract}
The main focus of this paper is to achieve and maintain optimum energy throughout the organization so as to minimize energy costs and improve power quality. Energy Audit is a systematic approach for decision-making in the area of energy management. A simple payback period calculation and formulation has been executed.
\end{abstract}

Keywords: $L C D, C R T, K W, K V A, K V A R$.

\section{INTRODUCTION}

\subsection{Energy Audit}

Energy audit is the basic and most important step for implementation of any effective energy management program. It tries to answer how, where and how much energy is used in the system. It provides an opportunity to look into energy use pattern and suggests way and mean of eliminating losses and improving the efficiency of the system. The immediate advantages obtained through energy audit are improved maintainability, reliability features coupled with reduction losses. Long term energy saving can be through the use of energy efficient equipment.

Today world has reached a stage, where energy is becoming major cost factor in almost all processes in life. Also, in many organizations energy and profit are closely related that the financial and energy audits are totally interlinked. Most of the organizations are weak in keeping track of the energy spent and hence consuming more energy than what is required for optimum work. Energy audit distinctly addresses these programs. Any saving in energy usage directly leads to the profitability of the organization. Hence for each organization it is necessary to pay more attention towards the energy saving opportunities available to them, through proper energy audit.

The objective of Energy Audit is to promote the idea of Energy Conservation in the campus of BMSIT. The purpose of the energy audit is to identify, quantify, describe and prioritize cost saving measures relating to energy use in the Academic blocks, hostel and canteen. The work eligible for Energy Audit Study should be directed towards:
- Identifying the areas of energy wastage and estimation of energy saving potential in Hostel, Departments and Institute Central Facilities.

- Suggesting cost-effective measures to improve the efficiency of energy use.

- Estimation of costs and payback period.

- Documenting results \& information generated through these activities.

- Identifying the possible usages of co-generation, renewable sources of energy (say Solar Energy, Biogas plant) and recommendations for implementation, wherever possible, with cost benefit analysis.

\subsection{Types of Energy Audit}

Basically energy audit is classified into following categories:

- Preliminary energy audit

- Detailed energy audit

\subsubsection{Preliminary Audit}

Preliminary Audit is performed in a limited time span. It mainly deals with improved better operation practices, proper utilization of energy, avoiding losses and wastages and also changing the process for energy efficiency. Preliminary audit focuses its attentions mainly on major energy supplies and demands, accounting at least for $70 \%$ of the total energy requirement in the system. It mostly involves the following steps:

- Forming a team with available in-house expensive.

- Carrying out walk through survey.

- Collecting system data pertaining to energy consumption, for last one year. 
- Developing energy consumption profile according to the data collection.

- Surveying the energy used in non working hours.

- Developing check list of normal working hours keeping the routine practices and functions.

Normally in-house experts are competent to conduct such preliminary audits and results are extremely useful in identifying the areas of extensive studies when going for detailed energy audit.

\subsubsection{Detailed Audit}

The detailed audit goes beyond quantitative estimates to costs and savings. It includes engineering recommendations and well defined projects with priorities. Detailed audit generally includes long-term measures such as technology, equipment, control logic and major modifications in system etc. The recommendations are usually long-term projects ranging from three to five years. It accounts approximately to $95 \%$ of energy utilized in the system. It involves a detailed technical analysis of each individual equipment, process to

- Quantify energy consumption by actual measurements over a period of time.

- Carryout detailed studies for various options available to modify.

- Implement the changes and continuously monitor the effects so as counter check the reduction in consumption.

- Integrate with the observations of preliminary audits.

\subsection{Energy Audit Methodology}

The methodology adopted for this audit is a three step process comprising of:

1. Data Collection: In preliminary data collection phase, exhaustive data collection was performed using different tools such as observation, interviewing key persons, and measurements with the help of Power analyzer.

2. Data Analysis: Detailed analysis of data collected was done using Elektra. The database generated by Elektra was used for producing graphical representations.

3. Recommendation: On the basis of results of data analysis and observations, some steps for reducing power consumption without affecting the comfort and satisfaction were recommended along with their cost analysis.

\subsection{Analysis of Power Consumption}

With the use of the software Elektra, we have analyzed the power consumption by equipment. Since hostel had the potential of maximum power conservation, hence equipment, application as well as location wise analysis of hostel was done. Here is the summary of the analysis presented in form of charts for better understanding.

\subsubsection{Main Block}

The Main Block of the BMSIT campus comprises of North and South block. The North block has Telecom and Electronics department whereas south block has Electrical and Mechanical department. The equipment wise analysis of the main block is as shown in graph.

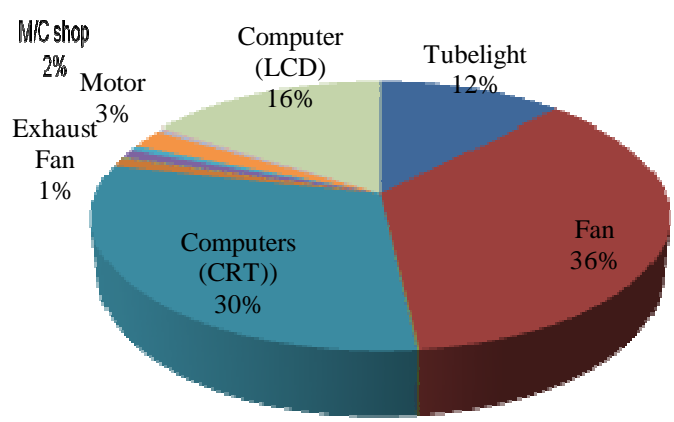

As $\%$ of total consumption of $11.568 * 10^{3} \mathrm{KW}-\mathrm{hr}$

As the data was collected during the month of April, it can be seen that fans have $36 \%$ share in power consumption. Computers come into picture with a combination of $46 \%$ share. This is the equipment where power can be saved by replacing the CRT monitor with LCD. The power consumed by LCD monitors is approximately half when compared to CRT. Further lightning has $12 \%$ share and it was observed that lights are not used during morning classes as sufficient lightning is there, so during calculation it was assumed that lightning is used only for 1 hour, Laboratories have $5 \%$ share of total consumption which includes electrical and mechanical labs (labs using computers are not included in this). Water cooler, exhaust fan, pumps also contribute to approximately $4 \%$.

\subsubsection{Computer Science Block}

This block comprises of Library, and MCA department. 


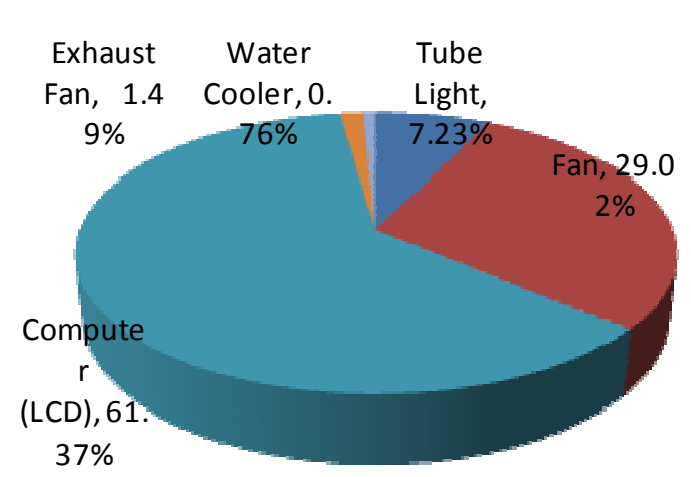

As $\%$ of total consumption of $9.7 * 10^{3} \mathrm{KW}-\mathrm{hr}$

The equipment wise analysis of this block suggests that Computers (LCD) are the maximum power consuming equipment with $61.37 \%$ of the total power consumption.. Fans account for $29.02 \%$ of total power consumption. Tube lights account for $7.23 \%$ which is quite low.

\subsubsection{Office}

The Office block has Allahabad bank and architecture department. The equipment wise analysis of office block suggests that maximum power is consumed by computers, which is $39 \%$ of the total power consumption. This is due to continuous use of computers in Office, which cannot be avoided. It was observed that all the monitors used in Office are CRT which is good for energy efficiency point of view. Tube lights and fan together share $56 \%$ of total consumption.

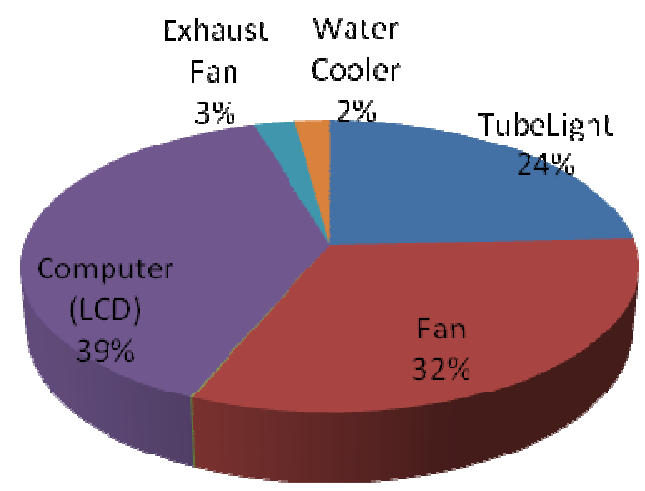

As $\%$ of total power consumption of $3.627 * 10^{3} \mathrm{KW}-\mathrm{hr}$

\subsubsection{Canteen}

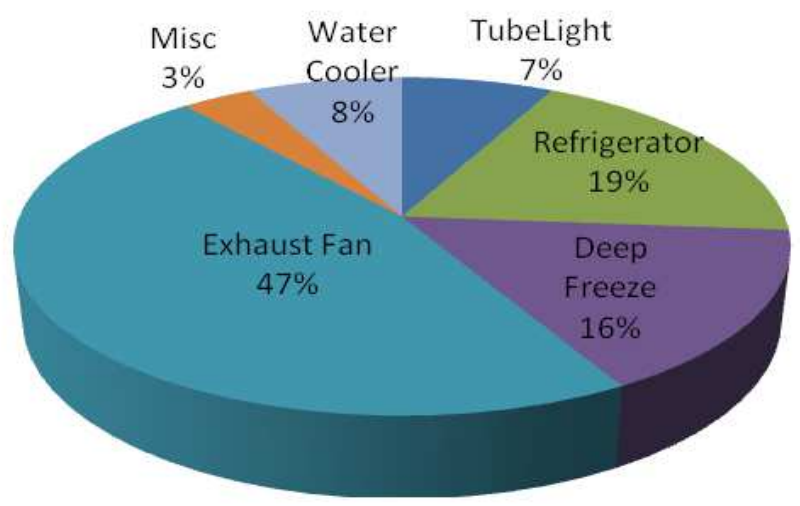

As $\%$ of total consumption of $0.431 * 10^{3} \mathrm{KW}-\mathrm{hr}$

The analysis of canteen suggests that maximum power consumption is in exhaust fan. Canteen has a total of 6 exhaust fan which is continuously in use. Exhaust fan share $47 \%$ of the total power consumption, Refrigerator and Deep Freeze contribute to $35 \%$ of the total power consumption, Tube light, Water cooler and miscellaneous contributes to $18 \%$. In canteen, electricity is being used wisely and has very low potential for reducing energy consumption.

\subsubsection{Hostels}

There are 2 hostels in BMSIT campus. They have capacity of 350 seats. Most of the rooms are double seated, but some rooms have single seat as well. In single seated rooms, one tube light of $36 \mathrm{~W}$ and one ceiling fan of $75 \mathrm{~W}$ has been provided. While in double seated rooms, two tube lights of $15 \mathrm{~W}$ each, one tube light of $36 \mathrm{~W}$ and one ceiling fan of $75 \mathrm{~W}$ is provided. In addition, hostel has two mess, Wi-Fi center, and Television room. The total power consumption of hostels during month of April

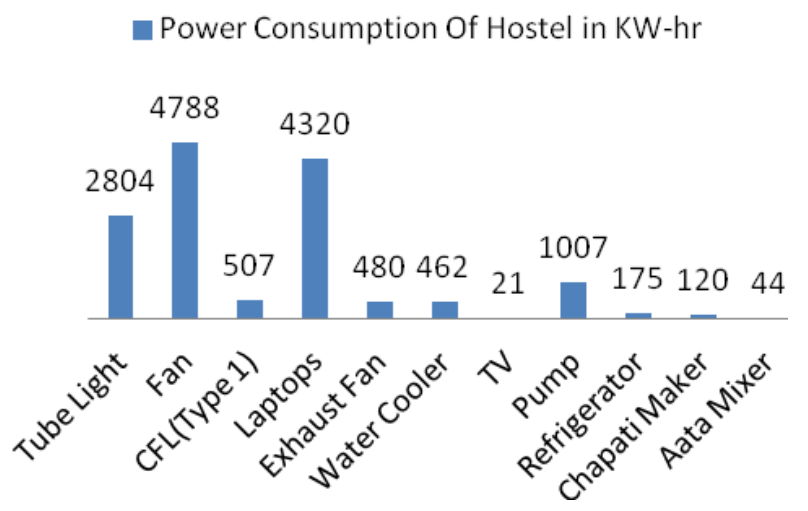


The total power consumption in month of April in hostel is $14.73 * 10^{3} \mathrm{KW}-\mathrm{hr}$.

\subsection{Power Factor Improvement}

The power factor of an AC electrical power system is defined as the ratio of the real power flowing to the load, to the apparent power in the circuit. Real power is the capacity of the circuit for performing work in a particular time. Apparent power is the product of the voltage and current of the circuit. In an electric power system, a load with a low power factor draws more current than a load with a high power factor for the same amount of useful power transferred. The higher currents increase the energy lost in the distribution system, and require larger wires and other equipment. Because of the costs of larger equipment and wasted energy, electrical utilities will usually charge a higher cost to industrial or commercial customers where there is a low power factor. If the power factor is low, for the same supply voltage \& load current drawn will be higher with low power factor, higher current will result in higher Copper loss i.e. $\left(I^{2} R\right)$ in cable \& transmission wires and increasing the transmission losses. It used to be two part tariff. A fixed portion based on the contracted demand \& variable charges based on the KWH consumed. It is a well-known fact that electricity users relying on alternating current with the exception of heating elements absorb from the network not only the active energy they convert into mechanical work, light, heat, etc. but also an inductive reactive energy whose main function is to activate the magnetic fields necessary for the functioning of electric machines. A low power factor is expensive and inefficient and some utility companies may charge additional fees when the power factor is less than 0.95. Induction motor efficiency can be improved by installing capacitor. Linear loads with low power factor (such as induction motors) can be corrected with a passive network of capacitors. Non-linear loads, such as rectifiers, distort the current drawn from the system. In such cases, active or passive power factor correction may be used to counteract the distortion and raise the power factor.

The approximate capacitor rating is shown in Table below

\begin{tabular}{|c|c|}
\hline $\begin{array}{c}\text { Motor nominal } \\
\text { rating }(\mathrm{KW})\end{array}$ & Capacitor power rating (KVAR) \\
\hline 1 to 1.9 & 0.5 \\
\hline 2 to 2.9 & 1.0 \\
\hline 3 to 3.9 & 1.5 \\
\hline 4 to 4.9 & 2.0 \\
\hline 5 to 5.9 & 2.5 \\
\hline 6 to 7.9 & 3.0 \\
\hline 8 to 10.9 & 4.0 \\
\hline 11 to 13.9 & 5.0 \\
\hline 14 to 17.9 & 6.0 \\
\hline 18 to 21.9 & 7.5 \\
\hline
\end{tabular}

\begin{tabular}{|c|l|}
\hline 22 to 29.9 & \multicolumn{1}{|c|}{10.0} \\
\hline 30 to 39.9 & $\begin{array}{l}\text { Approximately 40\% of motor } \\
\text { power }\end{array}$ \\
\hline 40 and above & $\begin{array}{l}\text { Approximately 40\% of motor } \\
\text { power }\end{array}$ \\
\hline
\end{tabular}

\section{RESULTS}

\subsection{Cost Analysis of Replacing CRT monitors with}

\section{LCD monitors:}

Total No. of computers with CRT monitors in Campus $=112$.

Power saved per monitor $=250 \mathrm{~W}$

Total Power saving $=28 \mathrm{~kW}$

Average Use of computers per year $=270 * 2 \mathrm{~h}=540 \mathrm{~h}$

Total Energy saved per year $=15120 \mathrm{kWh}$

Saving in Rs. Per year $=15120 * 2.70=$ Rs. 40824l-

Average Cost of Replacing each Monitor is

Total Cost of Replacing all monitors is

Rs. 6000\72,000\-

Capital Cost Recovery time $=16.46 y$.

Hence, the capital cost recovery time for replacing CRT monitors by LCD monitors is 16.46 years. Since the product life is more than that, the move is economically beneficial.

\subsection{Efficiency Comparison of Different Motors}

\begin{tabular}{|l|c|c|}
\hline $\begin{array}{l}\text { Efficiency At } \\
\text { Full Load }\end{array}$ & Slip Ring 3-Ф IM & Slip Ring 1-Ф IM \\
\hline $\begin{array}{l}\text { Before } \\
\text { Improving } \\
\text { Efficiency }\end{array}$ & $71.41 \%$ & $71.56 \%$ \\
\hline $\begin{array}{l}\text { After } \\
\text { Improving } \\
\text { Efficiency }\end{array}$ & $76.36 \%$ & $73.20 \%$ \\
\hline
\end{tabular}

Before Improving П $\quad$ After improving П

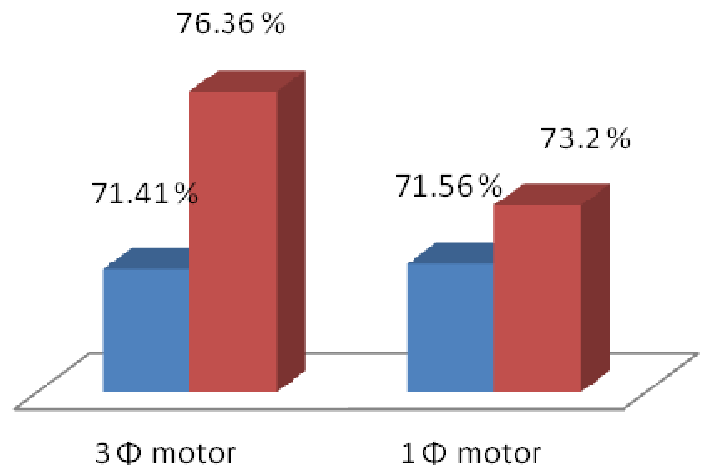


From the above graph it can be conclude that the efficiency can be improved by using power capacitor for AC machine. Also the cost and the payback analysis are calculated as shown below

\subsection{Three Phase Induction Motor}

- A 5hp $3 \Phi$ slip ring induction motor has an efficiency of $71 \%$ at full load

The losses of motor $=29 \%$

Hence total losses for $3.7 \mathrm{KW}=1.073 \mathrm{KW}$

- The total power supplied to the motor for one hour=3.9701KWh

- Assuming that motor is running 4 hours for a day, So for 1 month $=120 \mathrm{hrs}$

- The electricity bill rating of $3 \Phi$ slip ring induction motor for industries is Rs $15 / \mathrm{KWh}$

- The total units consumed in one month $=476.412 \mathrm{KWh}$

- $\quad$ The total running cost $=7146.18 \mathrm{Rs}$

\subsection{After Improving the Efficiency}

- When the efficiency of $3 \Phi$ slip ring induction motor is increased to $76 \%$ at full load. The losses in motor $=24 \%$

Hence total losses for $3.7 \mathrm{KW}=0.888 \mathrm{KW}$

- The total power supplied to the motor for one hour $=3.2856 \mathrm{KWh}$

- Assuming that the motor is running 4 hours for one day, So for one month $=120 \mathrm{hrs}$

- The electricity bill rating of $3 \Phi$ slip ring induction motor for industries is Rs $15 / \mathrm{KWh}$

- The total units consumed in one month=394.272KWh

- $\quad$ The total running cost = Rs 5914.081-

\section{CONCLUSIONS}

This audit was conducted to seek the opportunities to improve the energy efficiency of the campus. Beyond simply identifying the energy consumption pattern, this audit sought to identify the most energy efficient appliances. Moreover, some daily practices relating common appliances have been provided which may help reducing the energy consumption.

\subsection{General Observation}

- Use day lighting as much as possible with proper ventilation.

- It has been observed that the operators fail to turn of the equipment when not in use. So it is suggested to create awareness among the people about the important of Energy Conservation.

- Use Energy Conservation slogans in the work area as this motivates them to conserve energy.
Following are few slogans which could be used to motivate people to conserve energy

1. Energy misused cannot be excused.

2. Save one unit a day, keep power cut away.

3. The less you burn the more you earn.

4. When sunlight is bright switch off the light.

5. Today's wastage is tomorrow's shortage.

6. Energy earns or simply burns, choice is yours.

7. A thing which burns never returns.

8. Manage energy well to avoid damage.

9. One unit of energy saved is two units of energy generated.

10. Energy is life conserve it.

\section{REFERENCES}

[1] Guidelines for preparation of energy audit report. http://www.beeindia.in/energy

_manager_auditors/document/ea_em/Guidelines for preparation of audit report.pdf.

[2] Power factor correction equipment, http://www.ul.com/global / documents/ offerings/prespectives/regulators/technical /ul_power factor correction equipment.pdf.

[3] Hand book on energy audit and environmental management - Y.P Abbi and Shashank Jain.

[4] Power factor correction of $3 \Phi$ induction motor, http://www.electrical-insulation.org/enwiki/power factor correction of induction motor.

\section{BIOGRAPHIES}

Manjunatha Babu $\mathbf{P}$ obtained his B.E and M.E from Visvesvaraya Technological University, Bangalore University. Presently working as Assistant Professor in the Dept of Electrical and Electronics Engineering at BMS Institute of Technology, Bangalore, India His interests are in the area of power and Energy systems. Power System Operation and Control, Power Transmission and Distributions System Studies, FACTS Controllers.

Dr T.C. Balachandra obtained his $\mathrm{Ph} . \mathrm{D}$. degree from the Indian Institute of Science, Bangalore, India in 1995. He is currently working as Professor and Head, Department of Electrical and Electronics Engineering at BMSIT Bangalore, India. His research interests include vacuum insulation, micro and smart systems technology, insulation coordination \& condition monitoring of electrical \& electronic systems, software engineering methodologies and unified modeling language.

Ozwin Dominic Dsouza has received his Masters from National Institute of Engineering, Mysore, India. Currently working as Assistant professor in the Department of Electrical and Electronics Engineering at BMSIT Bangalore His research interests are in the field of Electric Drives and Systems, 
Control Systems, Converter Topologies and Electrical Machines.

Babu Naik G obtained his M.E from Indian Institute of Science, Bangalore. Presently working as Assistant Professor in the Dept of Electrical and Electronics Engineering at BMS Institute of Technology, Bangalore, India His interests are in the area of Power Systems, Power Electronics. 